\title{
A Study on Essence and Values of Canadian Aboriginal Cultures
}

\author{
Weili \\ Liaoning Police Academy \\ Dalian, China
}

Gao Xia

Chuxiong Normal University

\begin{abstract}
The aboriginal cultures, as the powerful testimony of the aboriginal ethnicity, have been passing on thousands of years by oral stories, traditional ceremonies and aboriginal education. The reasons why it could survive the severe oppression and cultural genocide were largely attributable to its inherent wisdom and reason, its scientific prediction and judgment. No one pictured that the inferior ethnicity, the under-cultivated red people could possess the modern harmonious life conception thousands of years ago. No one believed that the nomadic "savage" ethnicity could express the most honorable moral values of generosity and humanity, tolerance and bravery, courtesy and fortitude. A lot of fixed distorted images in our minds of the aboriginal peoples will be reversed up-side-down after you cast off your early prejudice and embark on the first hand-inhand contact with the aboriginal cultures. They are the great peoples, their cultures are the priceless treasures of the mankind worthy of being preserved and developed widely and passionately. The whole mankind is responsible for protecting this rare flower, making it constantly flourish amongst the world cultural circles.
\end{abstract}

Keywords: Canadian Aboriginals, Aboriginal cultures, Life philosophy, Lessons, Values.

\section{INTRODUCTION}

The aboriginal cultures, as the powerful testimony of the aboriginal ethnicity, have been passing on thousands of years by oral stories, traditional ceremonies and aboriginal education. Although experiencing severe oppression, forceful assimilation and even cultural genocide from the colonizers and subsequent governments, the aboriginals could still keep their cultures alive, revitalizing the vigor and vitality incessantly. This cannot be admitted no miracle. But how and why could they make it? The author personally agrees that it is attributable to the intrinsic and extrinsic factors in which the intrinsic one plays leading part. The extrinsic factor mainly involves the changing government policies, while the intrinsic factor demonstrates the aboriginal inherent wisdom and reason, its scientific prediction and judgment. It is just because of the distinctive aboriginal cultures that render the aboriginal peoples to survive and flourish. The paper will center on their distinctive cultures, the lessons from and reflections on them after prudent approaching.

\section{2. the Canadian Modern Policy and Significance of Maintaining Canadian Aboriginal Cultures}

\subsection{The Canadian Modern Ethnic Policy}

The Canadian folkloric multiculturalism placed emphasis on "celebrating Canadian differences", that is, on the idea that cultural diversity was in the heart of Canadian identity. [1] All cultures were seen as equal and precious, all contributing to the Canadian mosaic. One of the objectives of the amended Multiculturalism Act (which was passed on July, 21, 1988) stressed the acknowledgement of the freedom of all members of Canadian society to preserve, enhance and share their cultural heritage. Although the protection for the cultural heritage has become the legitimate activities, the status quo of the aboriginal culture is rather anxiety-ridden. Deterioration of Aboriginal cultural values has compounded the difficulties of identity and adjustment. Numerous aboriginal languages are currently under threat of disappearing because of pressure from the English (French) in the schools and media, with only three (Ojibwa, Cree, and Inuktitut) on relatively solid footing. The psychological effects derived from a sense of powerlessness, alienation, and irrelevances have been no less detrimental. Aboriginal individuals may transform this powerlessness and impotence into expression of selfhatred, the violent crime deaths, the alcohol addicts. Besides, more and more aboriginal youth don't know how to speak their mother tongue (while speak English or French fluently), nor endeavor to comprehend the real implications of the aboriginal cultural values. In light of the pessimistic 


\section{Wei Li \& Gao Xia}

phenomenon, it is imperative for the government and especially the aboriginal people to protect and carry forward the glamorous aboriginal culture and languages, for the culture almost equates with the ethnicity; the lost of the culture signifies the lost of the ethnic identity.

\subsection{The Significance of Maintaining Canadian Aboriginal Cultures}

The ethnic culture tends to play the crucial roles in making the ethnic policy, and therefore it is essential to re-evaluate the Aboriginal culture and comprehend its profound and specific implication, thus seeking the lapsus and demerits of the former policies due to the indifference to and ignorance of the aboriginal culture. This intelligent strategy will open the new path to establish the harmonious Aboriginal-government relationship on the basis of mutual understanding and respect. The more you approach the Aboriginal peoples, the more you'll learn about their complex cultural systems; the more you acquire their cultures, the more you'll understand their strong aspirations for self-determination and steadfast persistence in maintaining their own life philosophies, mother tongues, and larruping life styles. The Aboriginal culture, even to the mostly non-Aboriginal Canadians, is such an unfamiliar branch that they cannot bestow a thorough comprehension about it. Why? Because, in the first place, over the years Canadians have established the theory of inferiority that provided the rationale for controlling Aboriginal peoples as well as their resources of land; [2] in the second place, the previous Aboriginal polices (assimilation, marginalization, divide and conquer, integration) have denied opportunities to maintain the long-term steady and normal interactions, nor launch the constructive campaigns to promote the mutual understanding and communications, hence resulting in the discrimination and prejudice among the non-Aboriginal people and the grievance and hatred among the Aboriginal peoples, and even the 78-day overt conflicts in the Oka crisis. Nevertheless, as an indispensable component of the Canadians, whether the Aboriginal peoples or their cultures, should be respected, learned, and shared not only by the non-Aboriginal Canadians, but the people all over the world, for they are the important members of the world family, and their cultures inevitably and naturally belong to the world cultural heritage.

\section{The Aboriginal Cultural Treasure and Lessons from Their Philosophy}

The aboriginal culture, as the powerful testimony of the aboriginal ethnicity, has been passing on thousands of years by oral stories, traditional ceremonies and aboriginal education. The reasons why it could survive the severe oppression and cultural genocide were largely attributable to its inherent wisdom and reason, its scientific prediction and judgment. No one pictured that the inferior ethnicity, the under-cultivated red people could possess the modern harmonious life conception thousands of years ago. No one believed that the nomadic "savage" ethnicity could express the most honorable moral values of generosity and humanity, tolerance and bravery, courtesy and fortitude. A lot of fixed images in our minds of the aboriginal peoples will be reversed up-side-down after you cast off your early prejudice and embark on the first hand-in-hand contact with the aboriginal cultures. They are the great peoples, their cultures are the priceless treasures of the mankind worthy of being persevered and developed widely and passionately.

\section{Lessons from the Aboriginal Philosophy}

\subsection{The Basic Notion}

There always exists the core concept in each ethnic ideology which helps the ethnic members to explore the fundamental truth of the world: mysteries of the universe, the sources of the energy, and the power of the social development. In the aboriginal spiritual worlds, they believe that, in Mother Earth Spirituality, everything an Indian does is in a circle, and that is because the Power of the World always works in a circle, and everything tries to be round. The symbol of the circle is used by almost all the indigenous people in all parts of the world. Each symbol is used for many purposes. In the sacred hoop, all the creatures, despite physical or non-physical, are equal and tightly inter-dependent. Each life form requires the Amerindians to regard, and they have to consciously recognize a system that is infinitely perfect though difficult to be comprehended by the human brain. The system is known as the "great mystery". To endeavor to respect the holy traits existed in the relations among various life forms is the nature of Amerindians. is sacred, for they are the representation of the "great mystery". They are living in a very different world where every spiritual identity is acknowledged and respected. 
They have been conforming to a philosophy that is never to make the other life's existence and survival, especially those of the animals and the plants, threatened and endangered. They admitted and observed the laws and regulations, never jeopardized the liberties of the other creatures, which helped insure their most precious treasure: freedom. Long before, the Amerindian independence relied on their capabilities of gaining abundant food. In fact, the European's intervention led to the lost of the Amerindian's Eden paradise.

The most important teaching of the Medicine Wheel is that of "Balance". Through the wheel, we find a Holistic Balancing of the Spiritual, Mental, Emotional and Physical. The sacred circle is lifetime journey and will be traveled many times. No race or person is any greater or any less than the other. What one does affects the other, and it is to our advantage to work together to make life more pleasant. Remember that you are the Centre of the sacred circle (universe), and you direct your development, which affects the growth of everything around you. All you need is the willingness to learn and to walk in harmony to be balanced and maintain a good rhythm in life.

\subsection{Lessons from their life philosophy}

this Amerindian's ideology has accompanied them thousands of years assisting them in knowing the world with reason and wisdom, in conquering the hardship with faith and persistence, in accumulating the solidarity with the consent and experience, in recovering the vitality with inherent power and adaptability. As a matter of fact, the sacred hoop is not only cherished by the aboriginal peoples, but admitted and advocated by the whole world. The UN held a conference in 1977, in which the traditional Indian representatives presented the conference with their philosophy and prediction. The Wiseman from Sioux (one of the Aboriginal peoples) concluded his Indian siblings' feelings as follows:

Even though there is one slim hope to encourage the human race to continue living acting on the life style of the red people (we believe this style is the right one), we will catch on this precious opportunity to accomplish our cultivation to our Indians, to the American people, to the people all over the world, and this is the very intention that we come here European continent to educate and reeducate the human being, and only by this way are they capable of returning to the original doctrine.

From the above eloquent speech we can feel the extreme anxiety of the Aboriginal peoples towards the modern tragedy of civilization and the surviving threats all the human beings are confronted with. Their strong advocacy for protecting the natural world, our same homeland, and rethinking the negative side effects of the western civilization on the human progress encourages us to contemplate our so-called modern life styles, and over-developed social concept. Why do the Aboriginal peoples whom we have regarded as the under-cultivated, even "savaged" primal peoples go far beyond the civilized world in the comprehension about the human-nature relations? It is the people from the "primal tribe" who provides the "super-modern" man with the most thought-provoking lessons that provides the modern man with profound reflection and awakening revelation.

The first lesson we can learn from them is how to establish the harmonious relationship with the physical world, and how to guarantee the human being's progressively sound development, which is also the urgent issue to be resolved by the global villagers.

After the Industrial Revolution, the mankind began to exploit more and more natural resources to be utilized as the power sources, and only one century later, the air, the water, and the soil, nearly every living element was contaminated by the constant industrial development (involving the impulse of the economic profits) and the lack of the awareness to protect our environment (involving the ignorance of and indifference to the human-nature relations). Until the end of $20^{\text {th }}$ century, we are increasingly aware of the great importance of the natural world to the sustainable development of the human beings. The painful experiences taught us to value each element composing our Mother Earth, to respect every creature living under the same sky with us. However, who can envisage that this profound truth has been discovered and adhered to generation by generation among the Aboriginal peoples. They are not only the faithful believers in the Nature view, but the actual performers of this ideology.

Before they were praying, they showed the salute to the whole space and this activity reminded them of the position they have held in the creation of the whole: we are not the dominators; we must work with the other creatures to pursue the continual survival; when we are assembling, we are sitting together with the great universal hoop, and all the life forms are equal. 


\section{Wei Li \& Gao Xia}

The Amerindians respect all the life forms. In the Prairie culture, while the person who conducted the religious ceremonies were leaving the Indian lodge, he would express his respect to the stone and remarked: "I'm so grateful to you, the sacred sibling, for helping the human siblings purify themselves by contact of the perpetual power.

With the human survival more and more threatened by the natural disaster, we have to reflect upon what we have done to the Mother Earth in the previous years, we are obliged to absorb the aboriginal advanced conception and persistent practice in establishing the harmony with the natural world, respecting all the living forms, regarding all the creatures as the equal and friendly companions with us human being. To adhere to the natural laws, to conform to the harmonious and balanced concept, to integrate the human life to the part of the natural world, then the Mother Earth will restore its former balanced eco-system with varieties of rare species and abundant natural resources, especially the flourished and healthy human beings in progress. Although the present aboriginal peoples are living in poverty as a result of the comprehensive factors, their supreme natural view and corresponding activities undoubtedly offer us the best model and example to follow.

The second lesson we can learn from them is how to understand the wars and conflicts, how to deal with the conflicts among different cultural or ethnic groups, and how to interact with their siblings.

Although we are living in the modern era, attaining almost all the goals that the human beings are pursuing, our living space and qualities are imperiled by the regional conflicts, the racial conflicts, as well as the inter-ethnic conflicts. The world is hovered over by the shade of the terrorism (the extreme nationalism), the factual inequality, and the ethnic hatred as well. As to this point, let's pore over the Aboriginal concept about the wars and the arts of coping with the conflicts between the different Aboriginal groups.

To begin with, contrary to the common belief, the wars inside the Amerindians are very rare before the European explorers set foot on the North America; instead, the aboriginal peoples were living there thousands of years peacefully and prosperously, with the increasing population and congruent lifestyles. Of course, the conflict is unavoidable so long as the human beings engage in the social intercourse and productive work. While the aboriginal philosophies teach them that peace and harmony among different groups is the basic law to interaction. The harmony between the man and the nature and man to man composes the foundation stone of the human society, which determines the steady progress of the mankind, or vice versa. As a result, the aboriginal peoples never actively enkindle the wars, but the description of the blood-thirsty Amerindian savage is rather an absurd talk filled with schemes. The aboriginal peoples never attend a war for the sake of the war; they have to be involved in the battle to protect them from the unjust damage, to defeat the arm force for arm force, purposefully putting right the intertribal cannibalism. We can get revelation from the earlier works The Defeated Countries illustrating the core difference between the Aboriginal society and the European society: they took the different measures to deal with the conflicts. The war frequently happened in France, and the enemy was just inside the country; while in the Hurons (one branch of Aboriginal peoples) society, all the tribal members are the segments of the collective entity that the French society didn't exist. On the contrary, there were more King's infinite powers and severe tortures in France.

Next, the Amerindians have never attacked other ethnicities making them suffer the tortures and agony due to religious discrepancy and political allegation. On the whole American continent, though the Amerindians dispersed anywhere, they shared the same live philosophy: sacred hoop, they didn't confront each other on account of the diverse conceptions and cultures. Inside each nation, all the ethnic members expressed the deep affection to each other and admiration to the solidarity, which is consistent with the maxim of the sacred hoop: no race or person is any greater or any less than the other. Christopher Columbus (Italian navigator, the discoverer of the New World) and Sir Martin Frobisher (British navigator who discovered the Hudson Straight) had expressed their admiration and appreciation to such virtues. In Aboriginal society, Amerindians demonstrated the individual and collective virtues in their social lives and political programs; it was just because of this internal solidarity and commonly-shared concept that helped the Indian world maintain peaceful and flourishing state of existence.

Lastly, the rational tolerance and universal humanity contributed to maintaining and developing favorable interethnic relations. They respected the individual and entire life forms; they devoted to the 
public interests; they displayed the fearless heroism on trial; they assured that the dead ought to be respected, the frail ought to be protected; they showed greater generosity to the strange and absorbed them into their extended family; they were courteous to others, never disturbing them; they barely raged, but valued the individual freedom to a high degree. After all, they are the civilized nations cultivated by the nature. Most important, their social values embody the higher spiritual ease and selfconfidence. Supposed the two parties had some prejudice or disagreements, if one party presented with some petty gifts, such as the pearl or shell, which were accepted by the other, and then the original peaceful state would appear anew. How simple the solution to the conflict is! In fact, the requirements for keeping peace derive from the simple wishes of two sides, which demonstrate the human's nature and virtues: cordiality, humanity and tolerance. Putting aside all the desires and motives, what we need in our inner hearts is the mental peace, and this peace comes from the tolerant power of the mind, the humane nature, and the real respect and affections to the siblings and other life forms. It is just because of these human virtues that the aboriginal groups maintain calmness and restraint while being faced with confrontations without taking the drastically overt actions to front the government or other opponents. This is not the symbol of the weakness; conversely, this is the symbol of the considerate decision after contemplation and judgment. Furthermore, this is the human rational brilliance radiating the sense of love, respect, tolerance, generosity and humanity. The most complicated problem can be dealt with in the most simplified manner; the gratuity is a case in point. Presumably the aboriginal simple resolution will arouse the contempt and jeer from the highly civilized people, but the "well-educated" people should ask themselves the following questions: why are we involved in the conflicts and wars from year to year? Couldn't we endeavor to seek the selfinduced problems rather than attribute to the others' trespass? Isn't it the right time to re-evaluate the aboriginal arts of dealing with the human relations? The Aboriginal artless manner to deal with the conflicts presented us with an excellent model turning the complicated contradiction into a simple and reduced one. We are the siblings of the Earth; we need to maintain the harmonious relations not merely with the living space, but with each other so long as we long for surviving forever. As to the arts of human intercourse, we'd better rethink the aboriginal philosophy, studying its essence and learning their lessons, which is certain to improve our management of the future domestic and international conflicts.

\subsection{Aboriginal Values to Be Preserved and Developed}

The aboriginal peoples not only created the profound and rational core ideology, but possessed the multitudes of value systems corresponding to the sacred hoop, constructing a complete and distinctive cultural panorama. When we touch the abundant aboriginal values, we have to salute and applaud to their holistic orientation, inter-related point of view, their respect to others' independence and freedom in political affairs and daily lives, their open work ethnic, their mutualism, and a series of virtues manifested in generosity, fortitude, bravery and wisdom. The value system is the footstone of the ethnic cultures influencing the fundamental belief system and behaviors of the ethnic members. Disciplined by the traditional aboriginal value systems, the peoples gradually develop distinctive personality sustained by mostly Amerindians wherever they disperse, and this is the roots of Indians' survival through thousands of years. Respectfully, as the nomadic or agricultural ethnicity, they bring to the foreground the understanding and sublimation of the spirituality. Through participating into various ceremonies or self-reflection activities they explore the meanings of the life thoroughly and clearly. This spiritual self-reflection is a very effective and indispensable measure to obtain the mental peace and power, getting acquainted with the spiritual world and making sense the values of the living creatures, which is just what we the modern men are desperately short of under the severe living pressures. Nevertheless, have we thought about the consequences of merely working on and on without performing the spiritual reflection in time? A series of social problems, a pile of psychological problems, and a number of unsteady elements should largely relate to the more and more working pressures, less and less spiritual self-reflections. The more we see the aboriginal cultural deep-seated information, the more we appreciate and admire the creative and intelligent aboriginal peoples. It is the segregation and ignorance that leads to prejudice and discrimination. I believe so long as you bestow a little care and some proportions of the years of education to study the aboriginal glorious culture which is justified in playing a predominant part in the future progress of mankind, you will have a totally different view from the ethnocentrism (or Eurocentric) and White Superiority. Now, let's discuss some of the important values deserving studying and sharing. 


\section{Wei Li \& Gao Xia}

The holistic orientation [4]: Indian cultures, like most primal cultures, have a long-standing and wellintegrated orientation to the whole. All things are interrelated; everything in the universe is part of a single whole. Everything is connected in some way to everything else. It is only possible to understand something if we understand how it is connected to everything else. This is readily apparent in various aspects of Indian cultures, ranging from healing to social organization. This value possesses the same attribute of the Wholeness view of the Marxism, which is considered as the scientific worldview by the faithful in Marxism.

The personal differences: Native Americans traditionally have respected the unique individual differences among people. Common Native American expressions of this value include staying out of others' affairs and verbalizing personal thoughts or opinions only when asked. Many Native Americans as an expression of mutual respect expect returning this courtesy. To respect the others' privacy and freedom is the priority set by the western value, especially the American value. From this value, we can see the Aboriginal peoples underscore the individual space, and private affairs. These basic individual rights are also their focal concerns, which is conducive to undertake the democratic construction.

Vision quest: Vision quest is a time when an individual becomes more aware of his body, dreams and his own sense of self. It is a sacred ritual, a personal test that requires patience, endurance, and a strong will. The goal of the quest is to purify the body of negative thoughts, substances and feelings. When completed, the individual is left feeling energetic, alert and healthy. The Natives used this practice as a way to connect to their Supreme Being - to be open to the messages of the spirits.

Mutualism [5]: as a value, attitude, and behavior, mutualism permeates everything in the traditional Indian social fabric. Mutualism promotes a sense of belonging and solidarity with group members cooperating to fair group security and consensus. In the aboriginal community the value of mutualism promote the internal solidarity and the common development. From the Iroquois Nations to the National Brotherhood, the aboriginal siblings feel like constructing the consolidation to fight against the same enemies and strive for the deserving rights. In dealing with Indian students, this tendency must be incorporating cooperative activities on an equal footing with competitive activities in the learning environment.

The value of generosity and humanity: this value fits with pillar of fairness, take turns and share. Generosity is shown in caring; be kind, compassionate, and help people in need. In citizenship it fits with cooperation, be a good neighbor and protect the environment. Generosity is contributing to the well-being of aboriginal people. This moral value enabled the first European explorers to successfully pull through the dreadful winter, and go into the heartland of the America. Although the wellintentioned generosity helped a lame dog over a stile, the dog returned with the betrayal and slaughter. What astonished us is that the aboriginal peoples still hold their ground nourished with broad-minded generosity and humanity in the present competitive and cruel society. However, in fact, this is the most precious human nature deserved to be cherished by the whole mankind. The harmonious and peaceful human relations require the nourishment and support of the man's moral values; here the aboriginal ethic offers us the fabulous norm to pursue.

The value of reason and emotional restriction: the reason and emotional restriction is the central hallmark of the Aboriginal moral value system. In the evolving history of the aboriginal peoples we can track down their traces of being rational and restrained. They come to terms with their living conditions, in particular, they are content with their simple lives, and they relish the waveless live without ambition and misgiving in the pursuit of the top-level of man-and-nature relations. Comparatively speaking, the Euro-Canadians, they cannot control their emotions and possess too much ambition to conquer the natural world and human society, and the result is that they forfeit the vitality in life much earlier than the Amerindians. We can justly conclude that it is the quality of the reason and emotional restriction that helps the Amerindians to construct not only the man-and-nature harmony but the man-to-man peace monument in North America.

\section{CONCLUSION}

As the times progressing, the aboriginal peoples should, on one hand, actively preserve and promote their traditional cultural patterns, on the other hand, greatly encourage and develop the former to adapt to the new situation and requirements. To preserve but not to develop will cause the cultural 
stagnation; as a result, the preserved culture will become the archeological curiosities or the sacred relics for the people to reserve, and in time vanish out of the people's vision. We do hope the aboriginal cultural values will be developed and advocated to a maximum degree, not only by the Indians themselves, but the people living around them, and even the people across the world.

\section{ACKNOWLEDGEMENTS}

The research is financed by College Teaching Reform Research Project of Liaoning Province (2014) No. UPRP20140574: Multi Models to Develop College Students' 3C Abilities through Network College English Teaching and Learning Based upon Questions, by the Teaching Reform and Educational Quality Evaluation Research Important Project of Liaoning Education and Evaluation Academy (2015) No. PJHYZD15023: The Applied Research of One-to-One Digital Learning in EGP Teaching, and by the Twelfth Five-year Plan for Educational Science Project of Liaoning Province (2015) No. JG15DB170: A Study on Self-regulated Micro-course Learning and Implicitly Layered English Flipped Classroom.

\section{REFERENCES}

[1] Fleras, Augie and Jean Leonard Elliott. Unequal Relations: An introduction to race, ethnic, and abdominal dynamics in Canada. Scarborough, Ontario: Prentice- Hall Canada, Inc. (1999):305. Print.

[2] Frideres,J.S.,Gadacz, R.R. Aboriginal Peoples in Canada: contemporary conflicts, 6th ed. Toronto: Prentice Hall, (2001):1-2.Print.

[3] Xu Bingxun (translate). Self-account history of American Indian. Hohhot: Inner Mongolia University Press (2000):4-45. Print.

[4] Frideres, James \& Rene R. Gadacz (ed.). Aboriginal Peoples in Canada: Contemporary Conflicts. 6th Edition. Toronto: Prentice Hall (2001): 154. Print.

[5] Tanner, A. (ed.). 1983, The Politics of Indianness. Institute of Social and Economic Research, Memorial University of Newfoundland, St. John's, Newfoundland (1983): 296-297.Print.

\section{AUTHORS' BIOGRAPHY}

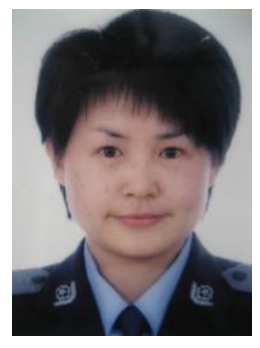

WEI Li: Born in Feb. 1972 in Liaoyang, China. BA of English, Liaoning Normal University, 1993, Master of English, Liaoning Normal University, 2007. She is a professor in Liaoning Police Academy, the author of one EI indexed paper. She has published more than 40 papers in Chinese academic journals including World Ethno-national Studies, Shandong Social Sciences, Social Sciences in Xinjiang, Academy, and 24 English papers published in international journals international conference proceedings. Her concentration centers around the Multicultural education, the Canadian Studies and network assisted Foreign Language Teaching.Professor Wei is a candidate for the Police Liaison Officers of the Public Security Ministry of China.

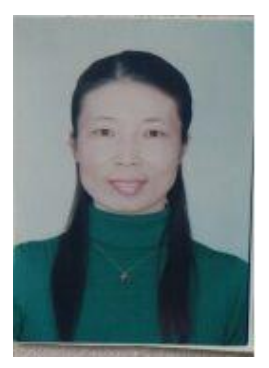

GAO Xia: Born in 1968 in Chuxiong, China. She received her Master degree in Teaching Chinese as A Second Language from Beijing Normal University, China in 2002. She is currently an associate professor in School of Foreign Languages \& Literature, Chuxiong Normal University, Chuxiong, China. Her research interests include the Second Language Acquisition, language and culture in English speaking countries.

Professor Gao is a member of the Chinese Association of Canadian Studies. 